\section{Thanks to our reviewers}

It is our custom, at year end, to acknowledge the vital contribution of our peer reviewers. Last year, we reached out to over 600 individuals for their assistance in reading, critically reviewing and providing feedback on papers submitted to the journal. The names of the 212 who agreed at least once are listed on the journal's webpage. I owe them a debt of thanks.

Stephen Lock in A Difficult Balance wrote that the validation of science is not the role of peer review; it is the role of time. But peer review is one of the crucial ways in which we seek to hold ourselves accountable for the state of our knowledge and its application. Is it perfect? Absolutely not. We miss things: error, false assumptions, bias, plagiarism and even fraud. But our peer referees spot more than they miss and the manuscripts we send to the publisher are better for the attention they have received.

As most who have undertaken to review will attest, it is a lengthy, sometimes maddening, exercise. Our editorial board members do more than their share of our peer review. But here I wish to acknowledge these 11 non-board members who each reviewed two or more papers for us last year: Francis Afukaar, Mary Aitken, Corey Basch, Peta Hitchens, Ben Hoffman, Mark King, Rebecca Mitchell, Mark Neider, Alex Quistberg, Fred Rivara and Steve Wirtz.

Brian D Johnston

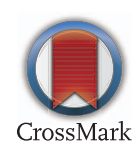

